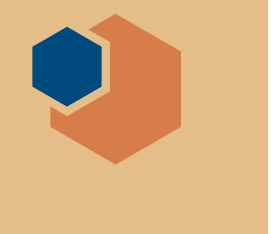

\section{Materials research to benefit from UK's industrial strategy}

$\mathrm{T}^{\mathrm{n}}$

he UK government managed to

take time out from negotiations to remove the country from the EU to publish a white paper laying out its industrial strategy. The Prime Minister, Theresa May, described the document, "Industrial Strategy_-Building a Britain Fit for the Future," as an attempt to "begin the development of a modern industrial strategy that would help businesses to create high quality, well paid jobs right across the country." As such the underlying rationale of the policy is to tackle the disparity in economic activity in different regions in the UK.

Research is a major component of the UK's new industrial strategy. The white paper makes much of the increase in spending on $\mathrm{R} \& \mathrm{D}$, building on the Autumn Budget announcement of what the government described as "the largest boost to R\&D support for 40 years." While other areas of government spending have seen constant cuts in recent years, spending on $R \& D$ will rise by $£ 2.3$ billion in $2021-2022$, taking the total spent on $R \& D$ in that year to $£ 12.5$ billion.

The strategy also sets out to encourage business investment in R\&D. One of the document's three headline "ideas" in the strategy is "Raise total research and development (R\&D) investment to 2.4 percent of GDP by 2027." R\&D investment in the UK currently stands at around 1.7 percent of GDP. Graeme Reid, professor of science and research policy at University College London and previously a senior civil servant in charge of research policy, says, "Realistically, R\&D investment will grow by 50 percent only if business investment rises by about $£ 10$ billion per year and the government share rises well beyond the recent $£ 2.3$ billion increase. The government will not sustain its higher level R\&D investment unless business keeps pace."

When it comes to where the government will spend on R\&D, the white paper sets broad ambitions rather than detailed plans for investment. It highlights five key concepts: ideas, people, infrastructure, business environment, and places. It then presents a strategy that will tackle these ideas through a series of "grand challenges": artificial intelligence and big data, clean growth, the future of mobility, and plans to "harness the power of innovation to help meet the needs of an ageing society." The aspiration of these grand challenges is "to put the United Kingdom at the forefront of the industries of the future."

The new industrial strategy sets the scene for a major shift in the control of research spending. Last April a new body, UK Research and Innovation (UKRI), brought together the research councils that manage most government spending on academic research and Innovate UK (IUK) (see the August 2016 issue of MRS Bulletin, p. 584). IUK operates at the interface between academic and industrial R\&D. Nick Cliffe, interim head of advanced materials research at IUK, sees the creation of UKRI as an opportunity to establish stronger connections between academic researchers and the businesses that can take their ideas and turn them into products and services. As he points out, one of the stated objectives of UKRI is to "promote stronger commercialisation, business and policy links and wider societal engagement with publicly funded research."

The new industrial strategy adds to last year's creation of the Industrial Strategy Challenge Fund. The white paper announced that the challenge fund will invest a further $£ 725$ million in new programs over the next four years "to capture the value of innovation." This is in addition to an original challenge fund round of $£ 1$ billion.

The Industrial Strategy Challenge Fund works through a series of funding rounds that invite bids 
for support in defined areas. Each challenge fund round operates as a series of standalone programs. The idea, Cliffe says, is that for each program there is a discrete and definable challenge where the UK has both the research capability and the industrial commitment to drive R\&D in the area.

The first wave of challenges included the Faraday Battery Challenge "for battery development for the electrification of vehicles." With a commitment to spend $£ 246$ million over the next four years, Cliffe describes "the Faraday" as being "all about clean and flexible energy and being able to deliver the batteries for the next generation" of electric vehicles. "There is so much expertise on batteries in the UK. Faraday is about translating it," Cliffe says.

The Faraday program, Cliffe explains, fits into the theme of the industrial strategy's Mobility Grand Challenge. The first wave of projects, with a total government investment of $£ 28$ million, runs from research into novel materials for batteries, through to the National Battery Manufacturing and Development Facility, an $£ 80$ million demonstration plant for pilot production of prototype batteries "at scale," big enough to be used in real applications. There were even projects on the recovery of materials at the end of a battery's life. It is a condition of winning grants that the industrial partners provide funds that at least match the government's input.

While much of the research in the Faraday program will take place in universities and companies around the country, there will also be a new Faraday Institution, based at Harwell near Oxford, as a focus for research nearer to the academic end of the R\&D spectrum. With a budget of $£ 65$ million over four years, the institution will establish a battery technology training program and will fund and direct research challenge projects in the academic sector.

A second wave of challenges, announced last autumn, committed a further $£ 725$ million, with several programs open to bids for materials research, including such concepts as "prospering from the energy revolution," reflecting the changing face of the energy system within the UK. Another area with a considerable advanced materials content, Cliffe says, was in "transforming construction," addressing the need to deliver housing in the most cost-efficient and clean way possible. In the run up to its move into UK Research and Innovation, IUK is preparing to launch a further call for bids for a second round of Faraday projects.

Michael Kenward
Chanette Armstrong appointed DOE Director of the Office of Technology Transitions

U S Secretary of Energy Rick Perry has announced the appointment of Chanette Armstrong as the Director of the Office of Technology Transitions (OTT) within the Department of Energy (DOE).

"Ms. Armstrong's engineering background coupled with her extensive private sector experience makes her an outstanding appointment for OTT Director," Secretary Perry says.

As the Director of OTT, Armstrong's responsibilities will extend across DOE's program offices, its 17 national laboratories, and its other research and production facilities across the country. She will also oversee DOE's Energy Investor Center, the Technology Commercialization Fund, and the coordination of technology transfer activities and best practices across the DOE complex.

In addition to serving as the Director of OTT, Armstrong will also serve as the DOE Technology Transfer Coordinator, an advisor to the Energy Secretary on technology transfer and commercialization activities. Armstrong will oversee and advance the DOE's efforts to spur innovation and accelerate the commercialization of early-stage technologies from the DOE's laboratories to the marketplace.

OTT was established in 2015 in order to expand the commercial impact of the DOE R\&D portfolio to advance the economic, energy, and national security interests of the country.

Armstrong is a registered patent attorney, holding a BS degree in electrical engineering from Carnegie Mellon University, a MBA degree from Long Island University, and a JD (Doctor of Law) from Rutgers, The State University of New Jersey Law School.

Last Fall, Perry announced \$19.7 million in funding through the OTT's Technology Commercialization Fund, supporting 54 projects across 12 national laboratories involving more than 30 private-sector partners. DOE's national laboratories have supported $R \& D$ that led to many technologies currently in the marketplace, including the batteries powering electric vehicles, the foundation of Internet servers, and the optical digital recording technology behind DVDs. According to DOE, these selections will further expand the department's efforts to catalyze the commercial impact of research, development, and demonstration activities to increase return on investment from federally funded work.

The recently funded projects include lithium anodes for electric vehicles (Argonne National Laboratory and alphaEn Corporation, Tarrytown, N.Y.), additive manufacturing of thermoelectric generators (Lawrence Livermore National Laboratory), biomaterials from nonwoody biomass (National Renewable Energy Laboratory and Sustainable Fiber Technologies, Renton, Wash.), and development of cost-effective quantum key distribution systems for the US power grid (Oak Ridge National Laboratory). $\square$

We welcome comments and feedback on these articles via email to Bulletin@mrs.org. 